\title{
1 Title: Short-term interferential transabdominal electrical stimulation did not change oral-rectal transit time in piglets
}

2 Running title: TES-IFC for piglet oral-rectal transit

\section{Authors: Andre YF Tan (PhD) 1,2, Magdy Sourial (B Vet Sci) 1,3, John M Hutson (MBBS, PhD, DSci) 1,2 4, Bridget R Southwell (PhD) 1,2,4.}

4 Institutional affiliations

1. Surgical Research Group, Murdoch Children's Research Institute, Parkville, VIC, Australia.

2. Department of Paediatrics, University of Melbourne, Melbourne, VIC, Australia.

3. Large Animal House Facility, Royal Children's Hospital, Melbourne, VIC, Australia.

4. Department of Urology, Royal Children's Hospital, Melbourne, VIC, Australia.

\section{Financial support}

Funding sources- This study was funded by the Australian National Health and Medical Research Council (NHMRC) Development Grant APP1000820 2010-2012 and Senior Research Fellowship (BS, 607396, 1023095), MCRI Theme Investment Funding and supported by the 'Victorian Government Operational Infrastructural Support Program'.

6 Authorship statement: All authors have contributed to and agreed on the content of the manuscript. Andre Tan (PhD student) designed the experiments, completed the ethics application, performed experiments, completed the data analysis, wrote the first draft and edited subsequent drafts. Magdy Sourial (animal house manager, operating theatre manager, surgeon and anaesthetist) oversaw animal husbandry, performed anaesthesia and placement of capsule containing plastic markers into the oesophagus, monitored health status of animals and performed euthanasia. John M. Hutson, supervisor involved in design and methods, performed check of data analysis for transit studies and edited manuscript drafts. Bridget Southwell, supervisor involved in design of experiments, ethics applications, performing experiments, data analysis and edited manuscript drafts.

Acknowledgements: We would like to thank Dr Yee lan Yik and Daniela Bodema for assistance with electrical stimulation, anaesthesia for placement of capsules and $\mathrm{x}$-ray procedures and Megan Dynan and Georgina Huan who assisted with animal husbandry and handling in pilot studies. We thank Shane

This is the author manuscript accepted for publication and has undergone full peer review but has not been through the copyediting, typesetting, pagination and proofreading process, which may lead to differences between this version and the Version of record. Please cite this article as doi:10.1111/ ner.12761. 
Osterfield and Karen Voss, animal house technicians who cared for the animals, monitored and fed animals and assisted with anaesthesia. We thank Stephen Lacey, Dr. Mita Pederson and Prof. Tim Cain, (RCH Medical Imaging Department), who consulted on study logistics and Stephen Lacey, Shauna Kehoe and Mark Turton who performed the $x$-ray imaging using a mobile $x$-ray machine.

7 Conflict of interest Statement

The authors do not hold any financial interest in the devices used in this study, which were purchased commercially. Andre Tan, John M. Hutson and Bridget Southwell hold a patent for the use of transcutaneous electrical stimulation to treat constipation. Bridget Southwell is also a co-author on a design patent for an electrical stimulation device that was not used in this study and consultant to GI Therapies, a company developing a new stimulation device.

Previous publication statement- Some of the control data was published in Tan AYF, Sourial M, Hutson JM, et al. Non-invasive measures of oral-rectal transit in young pigs. Livestock Science. 2016;188:13-20. None of these data have been previously presented in abstracts.

8 corresponding author

Corresponding Author: Dr Bridget R Southwell, Murdoch Children's Research Institute, Royal Children's Hospital, Parkville, 3052, Australia. bridget.southwell@mcri.edu.au, +61 393455069.

9 Acknowledgement section to add to paper after review:

Acknowledgements:

We would like to thank Dr Yee lan Yik and Daniela Bodema for assistance with electrical stimulation, anaesthesia for placement of capsules and x-ray procedures and Megan Dynan and Georgina Huan who assisted with animal husbandry and handling in pilot studies. We thank Shane Osterfield and Karen Voss, animal house technicians who cared for the animals, monitored and fed animals and assisted with anaesthesia. We thank Stephen Lacey, Dr Mita Pederson and Prof Tim Cain, (RCH Medical Imaging Department), who consulted on study logistics and Stephen Lacey, Shauna Kehoe and Mark Turton who performed the $x$-ray imaging using a mobile $x$-ray machine.

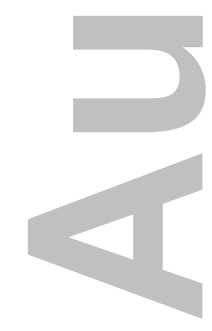




\begin{abstract}
Background: Transcutaneous electrical stimulation (TES) using interferential current (IFC) is a new therapeutic treatment for constipation. Clinical studies show that TES-IFC for 3-6 months improves colonic transit, but it is not clear if short-term stimulation affects transit or the effect requires longer to develop. The aim of this study was to determine if TES-IFC for only 4 days affects oral-rectal transit time in healthy pigs.
\end{abstract}

Methods: Twenty-two 4-5 week-old large white female piglets had transit studies during week 4 and week 5 by placing a capsule containing 18 radiopaque plastic markers in the oesophagus under anaesthetic followed by x-rays at 6, 30, 54 and 78 hours. Animals were randomly assigned to active or control groups. The active group received TES for $30 \mathrm{~min}$ daily for 4 days. Interferential current was applied through 4 electrodes $(4 \times 4 \mathrm{~cm})$, with 2 para-spinal just below the last rib and 2 on the belly at the same level. Stimulation was at $4000 \mathrm{~Hz}$ and $4080-4160 \mathrm{~Hz}$ with currents crossing through the abdominal cavity.

Results: Whole bowel transit times ranged from 7.7-72.2 hours, stomach transit from $<1$ to 63 hours, and bowel with rectum transit time from 5-53 hours. Transit times were the same for the control (median 28.4 hours) and TES-IFC (23.0 hours) groups in the prestimulation and stimulation weeks (control 23.0, TES-IFC 19.8 hours) with no change within or between groups.

Conclusion: Four days of half-hour TES-IFC daily in healthy 5 week-old piglets did not change oral-rectal transit time.

Keywords: transcutaneous electrical stimulation, gastrointestinal transit, constipation, neuromodulation, interferential current 


\section{Introduction}

Transcutaneous electrical stimulation (TES) using interferential current (IFC) is a new therapeutic treatment for constipation (1-6). Electrical currents are applied via self-adhesive electrodes on the skin, producing amplitude-modulated, sinusoidal current through tissues. Clinical studies utilising TES-IFC to treat urinary incontinence due to detrusor muscle instability, reported diarrhoea in patients as a sideeffect suggesting an increase in colonic motility and fluid secretion in these individuals $(7,8)$. In a study of 32 children receiving 1 hour of daily TES-IFC for 3 to 6 months, the number of bowel actions increased, abdominal pain decreased, stool consistency improved, and colonic transit improved (6).

The physiological mechanisms of TES-IFC are unclear and an animal model would be useful to optimise TES-IFC parameters. As the distribution and density of electrical fields at the skin-electrode-hydrogel interface and in biological tissues is volume dependent, a large animal model is required (9-11). Pigs are a good gastrointestinal human homologue, having similar anatomy, physiology, microbial gut flora and abdominal volume to humans (12). There are a number of studies describing colonic stimulation using implanted electrodes in animals (12-15), including one where transit time was observed (15). In that study, pigs ( $50 \mathrm{~kg} \pm 13 \mathrm{~kg}$ ) were given electrical stimulation via 3 electrodes implanted in the caecum for 20 minutes $(10 \mathrm{~V} / 120 \mathrm{~Hz})$ twice a day for only 6 days (15). There was a significant reduction in median colonic transit time of radio-opaque plastic markers post-stimulation when compared to placebo stimulation. Histological evaluation revealed a small amount of inflammation around the electrode (15). We have previously reviewed methods for studying compartmental transit in piglets (16) and established characteristics of transit using radio-opaque plastic markers.

Clinical studies show that TES-IFC for 3-6 months improves colonic transit (6), but it is not clear if shortterm stimulation affects transit or the effect requires longer to develop. The aim of this study was to determine if TES-IFC applied across the abdomen gave similar results to the implanted electrodes in 
pigs, i.e. determine if TES-IFC for only one week affects oral-rectal transit time. This study used radioopaque plastic markers and x-rays (16) to evaluate oral-rectal and colonic transit in the week before and during 4 days of TES-IFC in 5 week-old pigs, compared to pigs not given stimulation.

\section{Materials and Methods}

Ethical approval was obtained from the institutional Animal Ethics Committee (Projects A668: 20102013, A698: 2011-2014). The institutional animal ethics committee complies with Australian NHMRC rules for animal experimentation and international regulations including the declaration of Helsinki. Three-week-old 'Large-White' female, newly-weaned piglets were delivered and allowed to acclimatise in the animal research laboratory for 7-10 days. Animals were individually housed in $4 \mathrm{~m}^{3}$ pens and allowed to exercise and interact outside of the cages and pens at least once a day. Solid pig weaning feed (Barastoc ${ }^{\circledR}$ Ultrawean $^{\circledR}$ 150, Ridley Agriproducts, Melbourne, Australia) and water were made available ad libitum for the entire duration of the animals' stay (16). Animals mean weights were $8.5 \mathrm{~kg}$ at 4 weeks old, and $12.3 \mathrm{~kg}$ at 5 weeks old.

\section{Study Design}

Animals $(n=22)$ were treated in pairs and randomly assigned to either the Control or Active groups. There were 2 weeks of transit studies. All animals received no TES-IFC during the first transit study, while animals in the Active group received TES-IFC during the second transit study. Comparisons were made before and after TES-IFC (Active group) and between animals that did (Active group) or did not (Control group) receive TES-IFC.

\section{Stimulation Protocol}


Eleven pairs of animals were treated. Animals in the control group received the same handling procedures as the animals in the TES-IFC group (including placing a band around the abdomen to secure electrodes), but did not receive electrical stimulation. In the TES-IFC group, stimulation was applied for 30 minutes/day in the second week (Monday to Thursday, animals were 5 weeks old).

On the Friday before the stimulation period, animals were anaesthetised with isoflurane in oxygen (2\%) via inhalation and their bellies and backs shaved to ensure good electrode contact with the skin. On each day of stimulation, 4 adhesive electrode pads $(40 \mathrm{~mm} \times 40 \mathrm{~mm})$ were used to deliver interferential electrical current. Two electrodes were positioned on the dorsal surface of the animal (behind the last rib) and two on the belly (ventrally, Figure 1). Electrodes were connected so that the currents crossed (i.e. left front, right back) and secured to the animal with Elastoplast ${ }^{\circledR}$ self-adhesive tape (Beiersdorf Australia, North Ryde, New South Wales, Australia) and Surgifix ${ }^{\circledR}$ Tubular Elastic Net Bandages (Smith \& Nephew, Mount Waverley, Victoria, Australia, Figure 2). Current was delivered at $4000 \mathrm{~Hz}$ through one channel and 4080-4160 Hz in the other channel using the 4160 stimulator (FD09 model, Fuji Dynamics, Hong Kong), powered by $4 \times 1.2 \mathrm{~V} \mathrm{NiMH}$ rechargeable batteries. The current was turned up slowly until the pigs signalled discomfort by starting to kick at their belly and trying to rub the electrodes off against the cage wall. The level was turned down below this point to the highest comfortable level (maximum output by the stimulator is $40 \mathrm{~mA}$ ).

\section{Transit Studies}

Two transit studies were performed on each animal. The first transit study was performed one week prior to the commencement of TES-IFC (pigs were 4 weeks old), and the second transit study was performed during the week of TES-IFC (pigs were 5 weeks old). Stimulation started on Monday and the transit study started on Tuesday and finished on Friday so animals had 4 days of stimulation. We have previously described the transit method (16). In brief, animals has food removed at 0800 and were 
lightly anaesthetised with 2-5\% isofluorane at 0900. A gel capsule containing 18 markers (Sitzmarks, Konsyl Pharmaceuticals, Eaton, MD, USA, tri chamber marker PN 8100 24TC) was then inserted into the oesophagus through a laryngoscope, the animal was allowed to recover, given feed ad libitum and lightly anaesthetised again at 6, 30, 54 and 78 hours for x-ray imaging. At the end of the $5^{\text {th }}$ week, animals were sedated with ketamine $(5 \mathrm{mg})$ and euthanized with an injection of pentobarbitol (Virbac Pty Ltd, Milperra, Australia, 60mg/kg) in line with institutional ethical requirements.

\section{Analysis}

X-ray images were scored by AT and independently reviewed by a senior clinical investigator (JMH). The pig has a corkscrew large bowel and it was not possible to separate the small and large intestine in the $\mathrm{x}$ rays, so the locations described were the stomach, rectum and rest of the bowel. The number of markers in the stomach, rectum and rest of the bowel was determined at each time point.

Compartmental transit times were calculated using the method of Arhan et al. (17) and statistical analysis performed with GraphPad $^{\circledR}$ Prism $^{\circledR} 5$ (GraphPad Software, San Diego, California, USA). The compartmental transit time calculation provides a value that represents the mean time markers spend in a particular compartment (stomach, bowel, rectum or the whole animal). $P<0.05$ was considered statistically significant.

\section{Results}

\section{Evacuation of plastic markers}

Eighteen plastic markers in a capsule were placed in the oesophagus of lightly anaesthetised piglets and their location was determined at 6, 30, 54 and 78 hours by x-rays. The location of the stomach and the 
rectum were easy to distinguish, but the rest of the bowel could not be separated (Figure 3). Figure 4 shows the evacuation of markers from the stomach and from the animal overall during the stimulation week (TES-IFC animals received TES-IFC and controls did not) respectively.

Pigs were supplied with a small amount of feed after the markers were inserted, but there was a large range in rate that markers were evacuated from the stomach, with 5 pigs evacuating all markers by 6 hours and 3 evacuating no markers at this time. At 30 hours, 5 pigs still had some markers in the stomach, with one having 17 markers remaining. At 30 hours, all pigs had all some markers within the bowel, with half having evacuated half the markers. By 54 hours, 2 pigs had evacuated all markers and half had only one marker left. At 78 hours, 7 still had markers in the bowel, with one still retaining 17 markers.

The marker evacuation data were not normally distributed. The number of markers remaining in the stomach and whole bowel was the same for the control group and TES-IFC group at each time point. At 30 hours, a slight difference in number of markers between the groups was not significantly different $(P$ $=0.1$, Mann-Whitney test).

\section{Compartmental transit time of markers}

The compartmental transit time represents the average time markers spent in the respective locations. Bowel + rectal transit times were calculated by subtracting stomach transit times away from oral-rectal transit times. Figure 5 shows the compartmental transit times of markers in the stomach, bowel + rectum, and the total oral-rectal transit times, calculated according to the method described by (17). Transit values showed a high level of variability. Whole bowel transit times ranged from 7.7 hours to 72.2 hours. Stomach transit ranged from $<1$ hour to 63 hours, while bowel and rectum transit time ranged from 5 to 53 hours. The compartmental total transit times were the same for the control and 
TES-IFC groups in the prestimulation (median control 28.4, median TES-IFC 23.0 hours) and stimulation weeks (median control 23.0, median TES-IFC 19.8 hours) with no change within or between groups

\section{(Figure 5).}

\section{Behaviour of pigs during stimulation}

Pigs were able to move around during stimulation. During control stimulation pigs stood quietly in the pen and tried to eat the electrical leads. During Active stimulation pigs lay down after 5 mins of stimulation and went to sleep. When the stimulation stopped they immediately woke up and stood up. All stimulated (active group) pigs went to sleep. The current was turned up until pigs showed discomfort and then brought down.

\section{Discussion}

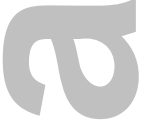

In this study, median oral-rectal transit in 5-week-old piglets was $21-24$ hours. TES-IFC at $4000 \mathrm{~Hz}$ for 30 minutes/day for 4 days did not cause any change in oral-rectal transit time in healthy 5 week-old piglets. The lack of change could be because TES-IFC has no effect on colonic motility, that stimulation was not for long enough, that the healthy pig's bowels were affected but responded by maintaining homeostasis or that the transit study was not reliable. This stimulation duration was chosen as human clinical studies in our group $(1,2)$ used 20-30 minutes' TES-IFC sessions daily for 1-2 months, and this study was designed to test the short-term effect of this stimulation. It is possible that a longer period of stimulation (i.e., longer each day or $\geq 2$ weeks of stimulation) may cause a change in oral-rectal transit time. More recent clinical studies $(3,6)$ had used longer daily stimulation (1 hour) and stimulation for 36 months.

Vaucher et al. (15) showed that short term stimulation of the pig caecum using surgically implanted electrodes did reduce transit time. In 6 animals, they performed 3 transit studies: pre-surgery, pre- 
stimulation and during colonic stimulation 4-5 weeks after the surgery (animals $>8$ weeks old). During the pre-surgical and pre-stimulation period, the mean transit times were $34 \pm 2.9$ hours (mean \pm SEM) and $36 \pm 6.7$ hours which is significantly slower than in this study but with less variation. During the stimulation period, the mean transit time dropped significantly to $19 \pm 5.3$ hours compared to both the pre-surgical and pre-stimulation transit times. This time was not significantly different to the transit time in the current study. The transit study method used by Vaucher et al. was different from this study. They gave 10 markers each day for 6 days and took one x-ray, while in this study, markers were given on one day and multiple x-rays were taken. This difference in methods may affect comparisons between the studies but not within the studies. Their pigs were older than the pigs in this study and transit time may stabilise in the older group. Piglets in our study weighed only $8-12 \mathrm{~kg}$ and were just at weaning.

The application of TES-IFC to pigs in this study may not be optimal. Future studies observing the effects of TES-IFC on colonic motility would benefit from an understanding of the electrical characteristics of the electrode-skin interface and variability due to skin impedance, as well as electrode characteristics.

Pigs are able to hold large particles in the stomach for long periods and this can produce great variation in the evacuation of markers from the stomach, complicating transit studies (16). Transit through the stomach varied from <6hours to $>30$ hours. In humans, transit through the stomach is rapid usually 3-4 hours (18).

\section{Limitations and future studies}

A limitation of this study was that TES-IFC was only administered for half an hour daily for 4 days to measure the short-term effect. Clinical studies report stimulation for months to overcome constipation, so longer studies are needed in the pigs. Future studies should perform TES for longer monitoring each 
week in some animals. This will require studies on larger pigs as they grow rapidly and handling for stimulation will be more difficult.

In addition, it is possible that homeostatic mechanisms are compensating for the effects of TES-IFC and the stimulation might only have effects if there is dysmotility. Future studies should therefore test TESIFC on constipated pigs. However, a constipated pig model has not been reported.

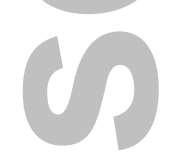

In this study, eating, drinking and defecation behaviour was not monitored. TES-IFC may have affected these behaviours. Future studies should monitor eating, drinking and defecation behaviour in order to determine if TES-IFC has any effects on these variables. This may be done by using a combination of scales, video surveillance and computer-controlled dispensing of food and water (19). Studies by others (19-21) provide good data about the behavioural patterns of pigs and form a useful comparative base.

During the stimulation, piglets lay down and went to sleep. This may indicate suppression of the sympathetic nervous system. It has been suggested that interferential stimulation over the lumbar region might inhibit sympathetics (1) and laying down and sleeping is in agreement with lowered sympathetic activity or increased parasympathetic activity. As sympathetic nerves inhibit the bowel, inhibiting the sympathetics might activate the bowel or release a brake. Against this, sleeping reduces bowel activity and this effect would slow bowel transit. In an ongoing study on 10 children aged 5-18 years, having 60 mins stimulation each day, half of the parents have observed the child becoming tired during the stimulation sessions (Southwell, personal communication). Future studies measuring the effects of TES-IFC across the abdomen on sympathetic/parasympathetic activity would be worthwhile. 
Gastric emptying and small bowel-rectal transit time were highly variable. The marker method we used in this study was specifically developed as it mimics the method used in human studies (16). We discussed the limitations of the x-ray transit method in a lot of detail in our previous paper describing the pig transit method (16). The technique using plastic markers with $\mathrm{x}$-rays is in standard use in humans but may not be the best way to measure transit in pigs as they needed sedation to insert the capsule and take $\mathrm{x}$-rays and sedation could affect bowel motility. An alternative is following transit of radioactive tracer (scintigraphy) with gamma camera images or using a Smart-pill. But these methods have not been reported in pigs. Access to gamma cameras and the corkscrew shape of the large bowel limits potential use of scintigraphy. The ability of the pig stomach to retain large particles might mean the Smartpill capsule would be trapped in the stomach.

The method we used calculates the average time that a marker spends in each compartment. If they all travel through the stomach in the first 6 hours, the calculation indicates that the average time a marker spent in a compartment is 0 hours. Physiologically, this is not meaningful, however, in order to gain a better estimation of marker transit time in each compartment, more frequent $\mathrm{x}$-rays need to be taken to cover gastric emptying. As this requires sedation, this could slow transit times of markers.

\section{Conclusion}

Four days of daily, half-hour TES-IFC in healthy, 5 week-old piglets did not cause a change in transit time. Further studies using longer stimulation each day and for a number of weeks are required and studies on constipated pigs would be valuable.

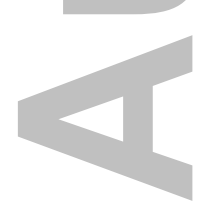




\section{References}

1. Chase J, Robertson VJ, Southwell B, Hutson J, Gibb S. Pilot study using transcutaneous electrical stimulation (interferential current) to treat chronic treatment-resistant constipation and soiling in children. Journal of Gastroenterology \& Hepatology. 2005;20(7):1054-61.

2. Clarke MC, Chase JW, Gibb S, Robertson VJ, Catto-Smith A, Hutson JM, et al. Decreased colonic transit time after transcutaneous interferential electrical stimulation in children with slow transit constipation. J Pediatr Surg. 2009;44(2):408-12.

3. Ismail KA, Chase J, Gibb S, Clarke M, Catto-Smith AG, Robertson VJ, et al. Daily transabdominal electrical stimulation at home increased defecation in children with slow-transit constipation: a pilot study. J Pediatr Surg. 2009;44(12):2388-92.

4. Watson T. The role of electrotherapy in contemporary physiotherapy practice. Man Ther. 2000;5(3):132-41.

5. Yik YI, Cain TM, Tudball CF, Cook DJ, Southwell BR, Hutson JM. Nuclear transit studies of patients with intractable chronic constipation reveal a subgroup with rapid proximal colonic transit. J Pediatr Surg. 2011;46(7):1406-11.

6. Yik YI, Ismail KA, Hutson JM, Southwell BR. Home transcutaneous electrical stimulation to treat children with slow-transit constipation. J Pediatr Surg. 2012;47(6):1285-90.

7. Emmerson C. A preliminary study of the effect of interferential therapy on detrusor instability in patients with multiple sclerosis. Australian Journal of Physiotherapy. 1987;33:64-5.

8. Kajbafzadeh A-M, Sharifi-Rad L, Baradaran N, Nejat F. Effect of Pelvic Floor Interferential Electrostimulation on Urodynamic Parameters and Incontinency of Children With Myelomeningocele and Detrusor Overactivity. Urology. 2009;74(2):324-9.

9. McAdams ET, Jossinet J, Lackermeier A, Risacher F. Factors affecting electrode-gel-skin interface impedance in electrical impedance tomography. Medical and Biological Engineering and Computing. 1996;34(6):397-408.

10. Patriciu A, Yoshida K, Struijk JJ, DeMonte TP, Joy MLG, Stodkilde-Jorgensen H. Current density imaging and electrically induced skin burns under surface electrodes. Biomedical Engineering, IEEE Transactions on. 2005;52(12):2024-31.

11. Yoon RS, DeMonte TP, Hasanov KF, Jorgenson DB, Joy MLG. Measurement of thoracic current flow in pigs for the study of defibrillation and cardioversion. Biomedical Engineering, IEEE Transactions on. 2003;50(10):1167-73. 
12. Aellen S, Wiesel PH, Gardaz JP, Schlageter V, Bertschi M, Virag N, et al. Electrical stimulation induces propagated colonic contractions in an experimental model. Br J Surg. 2009;96(2):214-20.

13. Sanmiguel CP, Casillas S, Senagore A, Mintchev MP, Soffer EE. Neural gastrointestinal electrical stimulation enhances colonic motility in a chronic canine model of delayed colonic transit.

Neurogastroenterology \& Motility. 2006;18(8):647-53.

14. Sevcencu C, Rijkhoff NJ, Gregersen H, Sinkjaer T. Propulsive activity induced by sequential electrical stimulation in the descending colon of the pig. Neurogastroenterol Motil. 2005;17(3):376-87.

15. Vaucher J, Cerantola Y, Gie O, Letovanec I, Virag N, Demartines N, et al. Electrical colonic stimulation reduces mean transit time in a porcine model. Neurogastroenterol Motil. 2009.

16. Tan AYF, Sourial M, Hutson JM, Southwell BR. Non-invasive measures of oral-rectal transit in young pigs. Livestock Science. 2016;188:13-20.

17. Arhan P, Devroede G, Jehannin B, Lanza M, Faverdin C, Dornic C, et al. Segmental colonic transit time. Diseases of the Colon \& Rectum. 1981;24(8):625-9.

18. Sarosiek I, Selover KH, Katz LA, Semler JR, Wilding GE, Lackner JM, et al. The assessment of regional gut transit times in healthy controls and patients with gastroparesis using wireless motility technology. Aliment Pharmacol Ther. 2010;31(2):313-22.

19. Musial F, Kowalski A, Enck P, Kalveram K-T. A computer-controlled, long-term recording system for studying eating, drinking, and defecation behavior in miniature pigs. Physiology \& Behavior. 1999;68(1-2):73-80.

20. Ingram DL, Walters DE, Legge KF. Variations in Motor Activity and in Food and Water Intake over $24 \mathrm{~h}$ Periods in Pigs. The Journal of Agricultural Science. 1980;95(02):371-80.

21. Bigelow JA, Houpt TR. Feeding and drinking patterns in young pigs. Physiology \& Behavior. 1988;43(1):99-109.

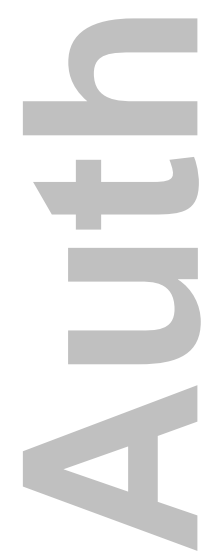




\section{Figures}

Figure 1: Location of electrodes for TES-IFC A): Dorsal view showing electrodes located either side of spine behind the last rib B) Electrodes were located on the abdomen at the same level; C) Electrodes were connected so that currents crossed within the abdomen creating two interfering currents. Current was delivered at $4000 \mathrm{~Hz}$ through channel 1 and $4080-4160 \mathrm{~Hz}$ through channel 2.

Figure 2: A) Piglet prepared for electrical stimulation. Electrodes are covered by a tubular elastic net bandage commonly used for surgery. The net bandage held the electrodes securely against the skin and provided electrical insulation if the pig rubbed against the metal cage. Piglets were accustomed to handling and to the bandage over 3-4 days before electrodes were added. B) Piglet during TES-IFC. After 5 mins, piglets laid down and appeared to sleep. Animals continued to breath comfortably and woke up as soon as the stimulation stopped.

Figure 3. X-ray image showing location of plastic markers at A \& B) 6 hours and C \& D) 30 hours after ingestion. A \& C are ventral images, B \& D are lateral images. Eighteen markers were placed in the oesophagus under light anaesthesia. A white circle has been placed near to each marker to aid visualisation. Insert in A) shows gel capsule containing 18 markers and 3 markers outside the capsule. Marker diameter is $4 \mathrm{~mm}$. A \& B) 6 Hours after ingestion: The air in the stomach is seen as a darker region. Markers are accumulated in the stomach. C \& D) 30 Hours: 2 Markers remain in the stomach and the rest are distributed in the bowel, but it is difficult to distinguish small and large bowel so these were grouped as one compartment. The pig large bowel is folded into a corkscrew and can locate on the left side or ventral to the small bowel. The large gas-filled section on the lower right is the caecum, clearly visible at 30 hours but not at 6 hours.

Figure 4: Marker evacuation in Control and Active pigs for A) the stomach and B) the whole bowel when the animals were 5 weeks old. TES-IFC was administered to animals in the Active group, while Controls received the same handling and experimental preparation, but no stimulation. Control (no electrical stimulation) - circles, active (TES-IFC for 30 mins per day) squares. There was wide variation in the movement of markers out of the stomach with all 
markers out of the stomach between 6 and 30 hours. $n=11$ per group. Median \pm Interquartile Range (IQR).

Figure 5: Segmental transit times for A) Total, B) stomach and C) bowel with rectum.

Individual compartmental transit times for each animal (with median \pm Interquartile Range $(I Q R))$. When pigs were 4 weeks old, no TES-IFC was administered to control or active TES-IFC group. When they were 5 weeks old, TES-IFC was administered to animals in the Active group, while Controls received the same handling and experimental preparation, but no stimulation. There were no significant differences in the median transit rates (Paired Friedman test, with Dunn's post-tests). $A=$ Active,$C=$ control, $T E S-I F C=$ transcutaneous electrical stimulation with interferential current. $\mathrm{n}=11$ per group.

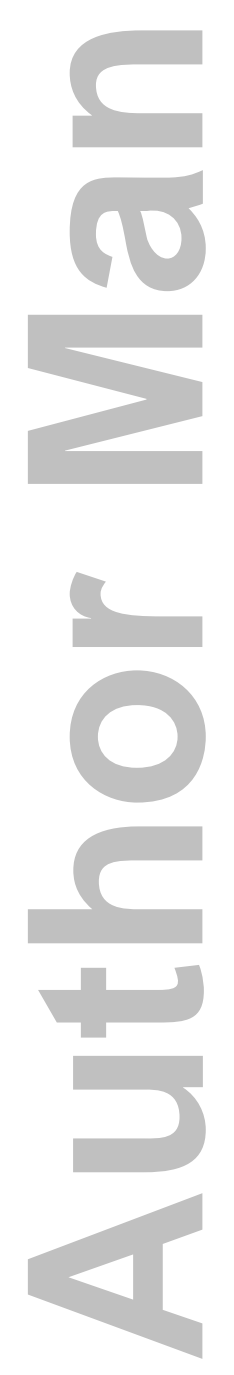




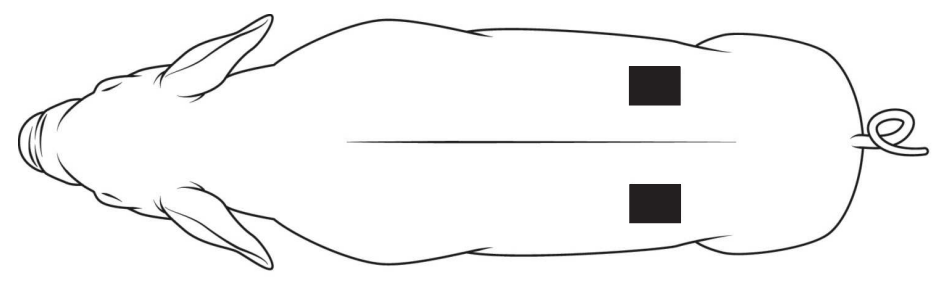

B
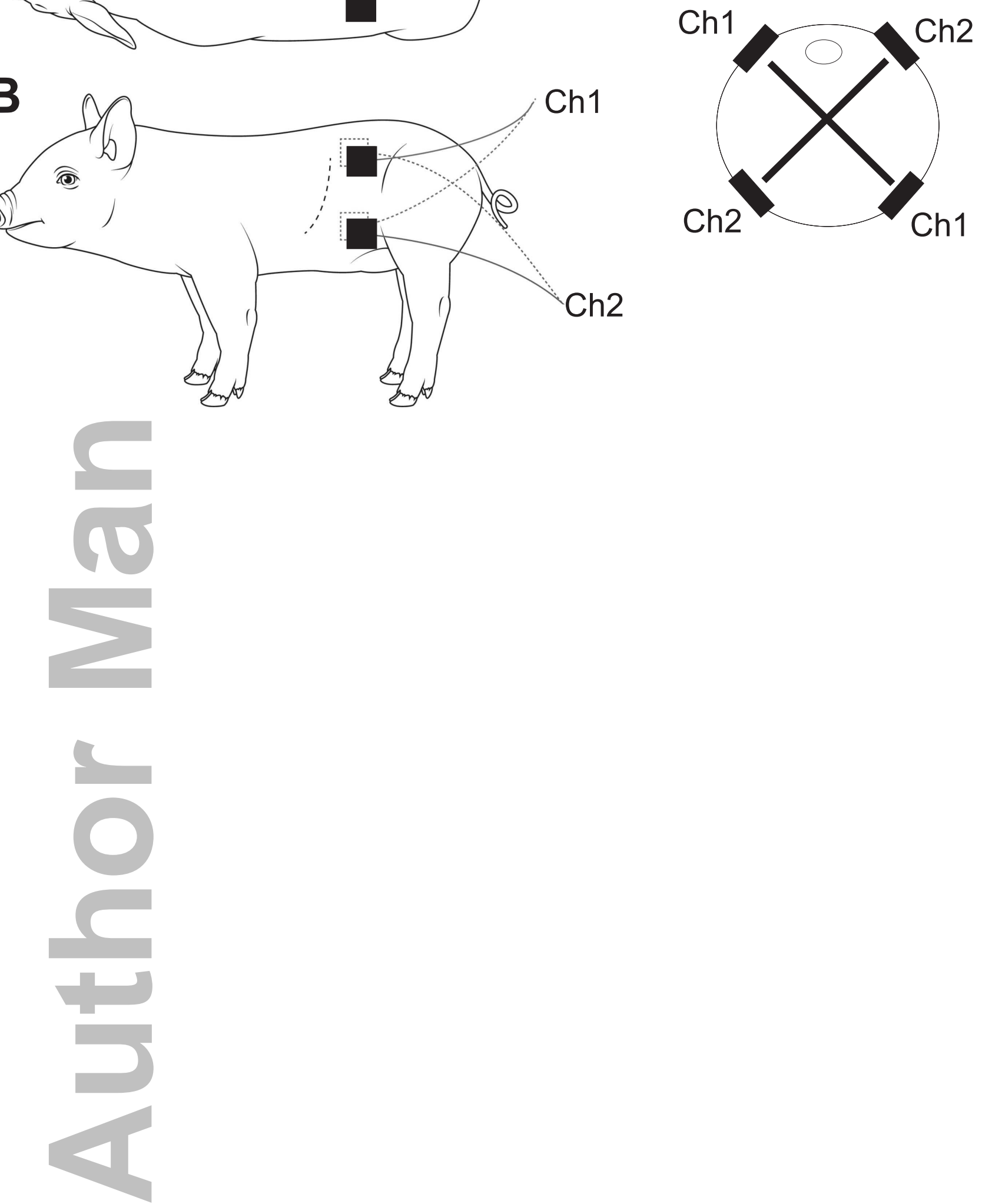

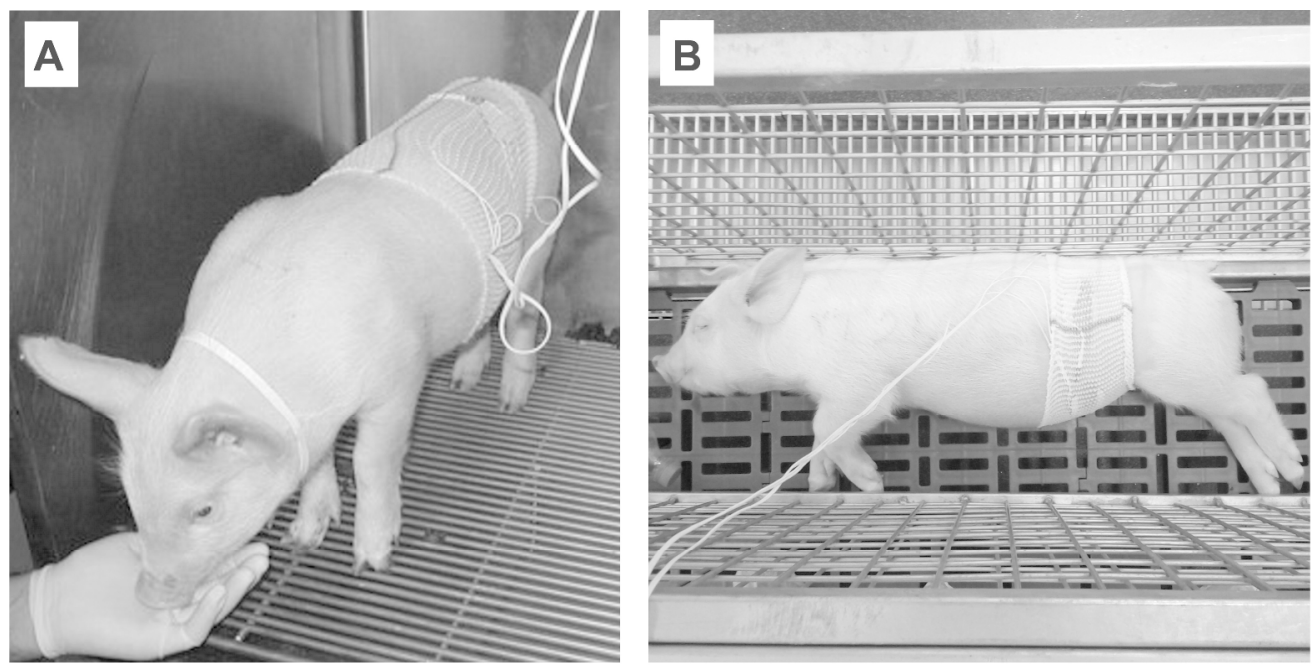

Figure 2: A) Piglet prepared for electrical stimulation. Electrodes are covered by a tubular elastic net bandage commonly used for surgery. The net bandage held the electrodes securely against the skin and provided electrical insulation if the pig rubbed against the metal cage. Piglets were accustomed to handling and to the bandage over 3-4 days before electrodes were added. B) Piglet during TES-IFC. After 5 mins, piglets laid down and appeared to sleep. Animals continued to breath comfortably and woke up as soon as the stimulation stopped. 

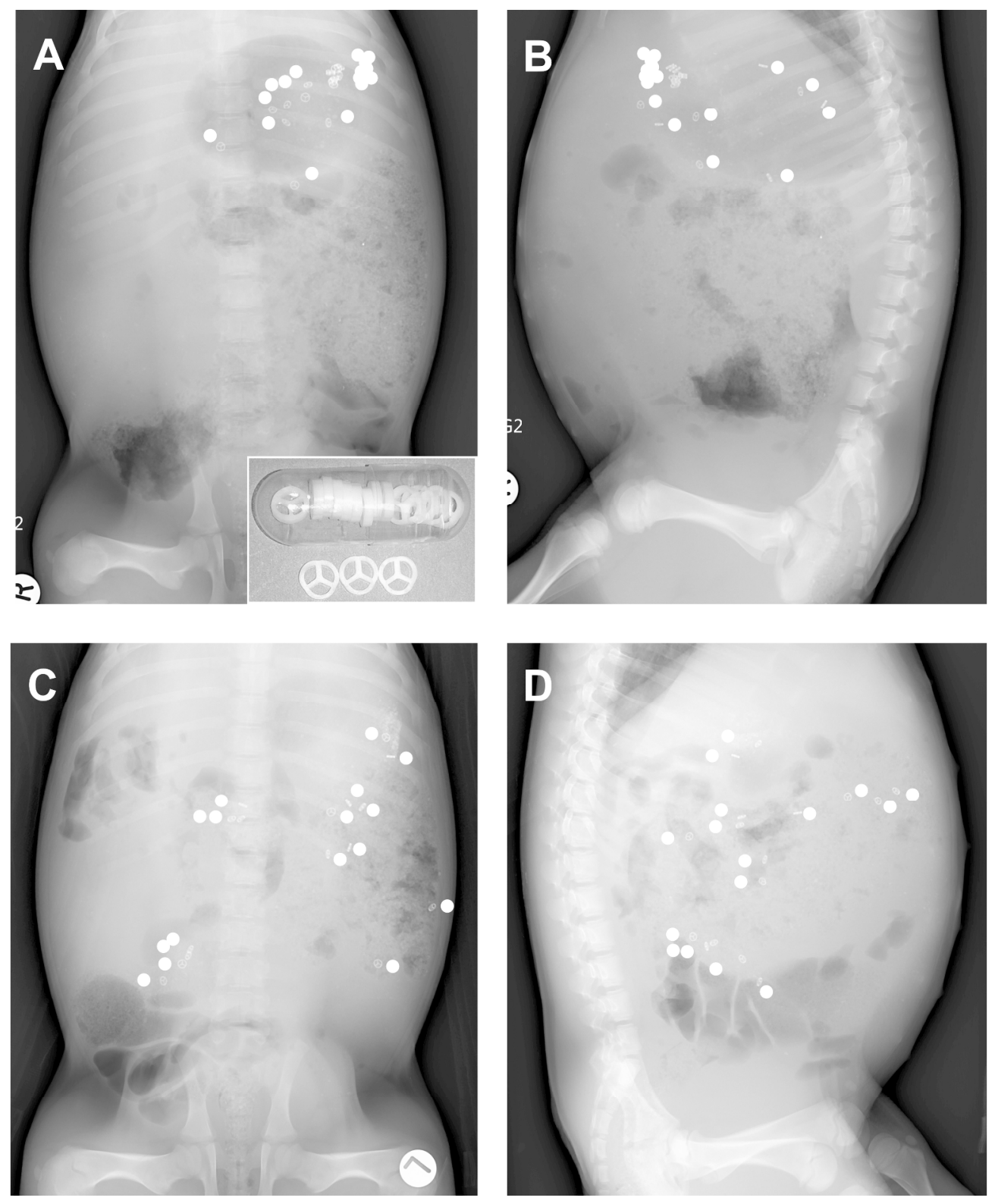

Figure 3: X-ray image showing location of plastic markers at A \& B) 6 hours and C \& D) 30 hours after ingestion. $A \& C$ are ventral images, $B \& D$ are lateral images. Eighteen markers were placed in the oesophagus under light anaesthesia. A white circle has been placed near to each marker to aid visualisation. Insert in A) shows gel capsule containing 18 markers and 3 markers outside the capsule. Marker diameter is

$4 \mathrm{~mm}$. A \& B) 6 Hours after ingestion: The air in the stomach is seen as a darker region. Markers are accumulated in the stomach. C \& D) 30 Hours: 2 Markers remain in the stomach and the rest are distributed

in the bowel, but it is difficult to distinguish small and large bowel so these were grouped as one compartment. The pig large bowel is folded into a corkscrew and can locate on the left side or ventral to the small bowel. The large gas-filled section on the lower right is the caecum, clearly visible at 30 hours but not at 6 hours. 
B

\section{Gastric}

0

2

5

6

7

8

9

0

2

3

7

8

9

0

2

3

4

5

7

8

9

0

2

.

.

7
8
9
0
1
2
3
4
5
6
7
8
9

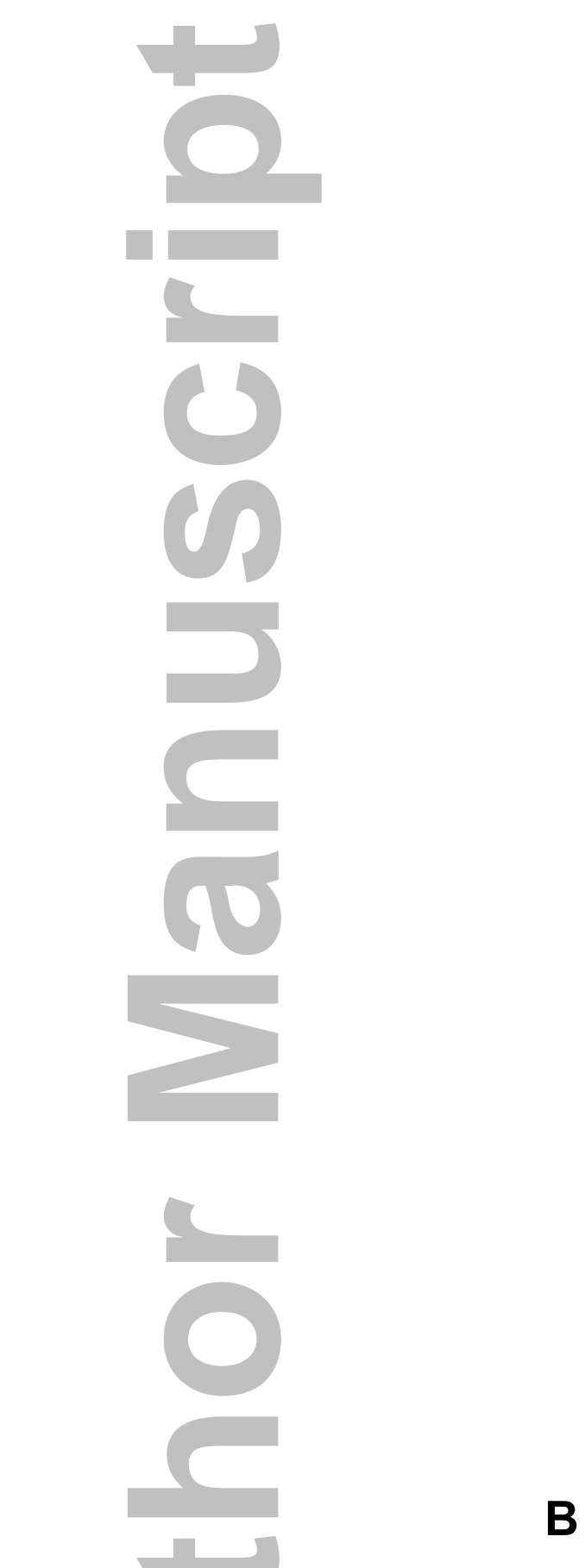

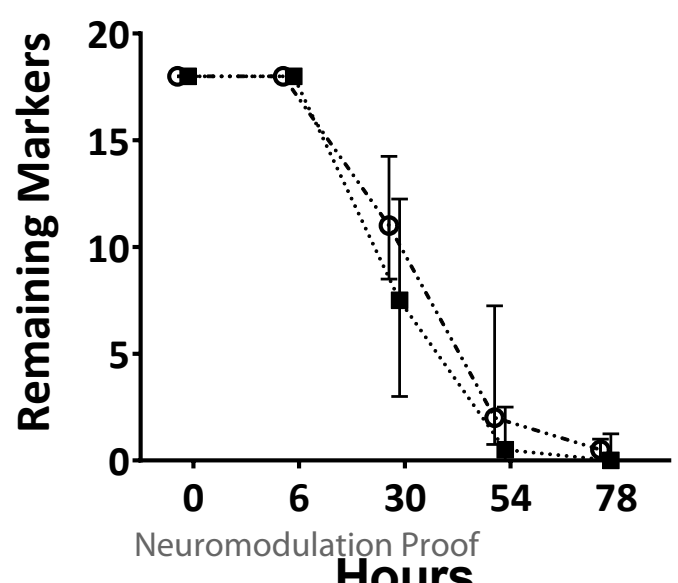

Hours 


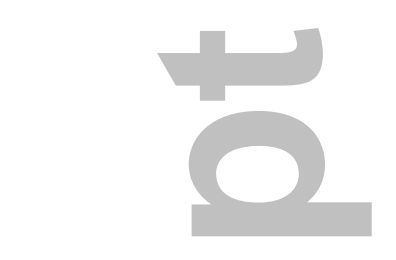

$$
\begin{aligned}
& 4 \\
& 5 \\
& 6 \\
& 8 \\
& 9 \\
& 0
\end{aligned}
$$$$
\text { . }
$$

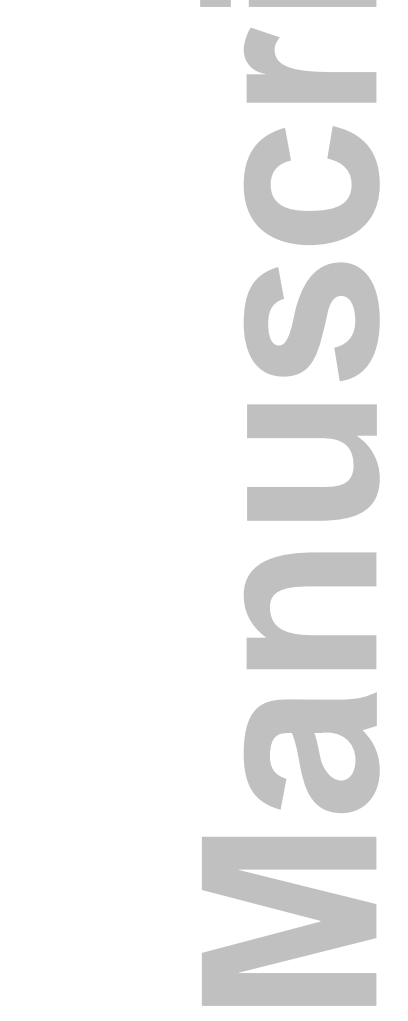

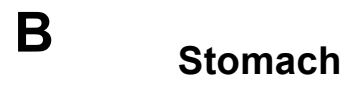
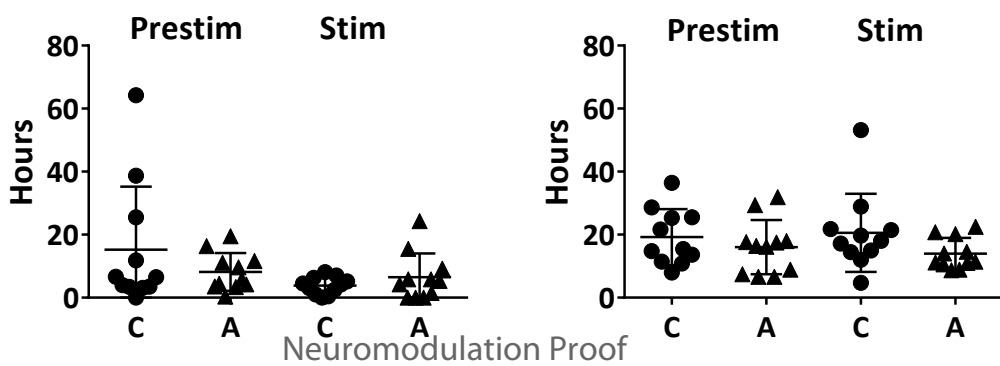

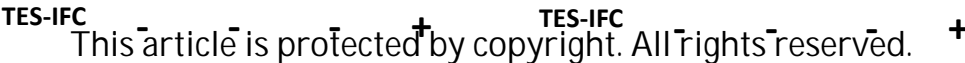




\section{Figures legends}

gure 1: Location of electrodes for TES-IFC A): Dorsal view showing electrodes located either side of spine behind the last rib B) Electrodes were located on the abdomen at the same level; C) Electrodes were connected so that currents crossed within the abdomen creating two interfering currents. Current was delivered at $4000 \mathrm{~Hz}$ through channel 1 and $4080-4160 \mathrm{~Hz}$ through channel 2.

Figure 2: A) Piglet prepared for electrical stimulation. Electrodes are covered by a tubular elastic net bandage commonly used for surgery. The net bandage held the electrodes securely against the skin and provided electrical insulation if the pig rubbed against the metal cage. Piglets were accustomed to handling and to the bandage over 3-4 days before electrodes were added. B) Piglet during TES-IFC. After 5 mins, piglets laid down and appeared to sleep. Animals continued to breath comfortably and woke up as soon as the stimulation stopped.

Figure 3. X-ray image showing location of plastic markers at A \& B) 6 hours and C \& D) 30 hours after ingestion. A \& C are ventral images, B \& D are lateral images. Eighteen markers were placed in the oesophagus under light anaesthesia. A white circle has been placed near to each marker to aid visualisation. Insert in A) shows gel capsule containing 18 markers and 3 markers outside the capsule. Marker diameter is $4 \mathrm{~mm}$. A \& B) 6 Hours after ingestion: The air in the stomach is seen as a darker region. Markers are accumulated in the stomach. C \& D) 30 Hours: 2 Markers remain in the stomach and the rest are distributed in the bowel, but it is difficult to distinguish small and large bowel so these were grouped as one compartment. The pig large bowel is folded into a corkscrew and can locate on the left side or ventral to the small bowel. The large gas-filled section on the lower right is the caecum, clearly visible at 30 hours but not at 6 hours.

Figure 4: Marker evacuation in Control and Active pigs for A) the stomach and B) the whole bowel when the animals were 5 weeks old. TES-IFC was administered to animals in the Active group, while Controls received the same handling and experimental preparation, but no 
stimulation. Control (no electrical stimulation) - circles, active (TES-IFC for 30 mins per day) squares. There was wide variation in the movement of markers out of the stomach with all markers out of the stomach between 6 and 30 hours. $n=11$ per group. Median \pm Interquartile Range (IQR).

Figure 5: Segmental transit times for A) Total, B) stomach and C) bowel with rectum.

Individual compartmental transit times for each animal (with median \pm Interquartile Range (IQR)). When pigs were 4 weeks old, no TES-IFC was administered to control or active TES-IFC group. When they were 5 weeks old, TES-IFC was administered to animals in the Active group, while Controls received the same handling and experimental preparation, but no stimulation. There were no significant differences in the median transit rates (Paired Friedman test, with Dunn's post-tests). $A=$ Active,$C=$ control, TES-IFC = transcutaneous electrical stimulation with interferential current. $n=11$ per group.

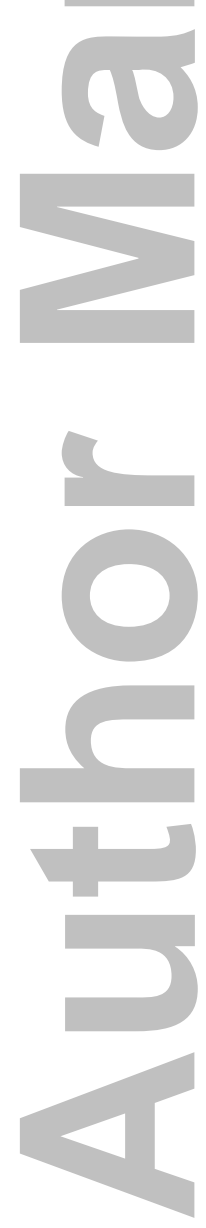




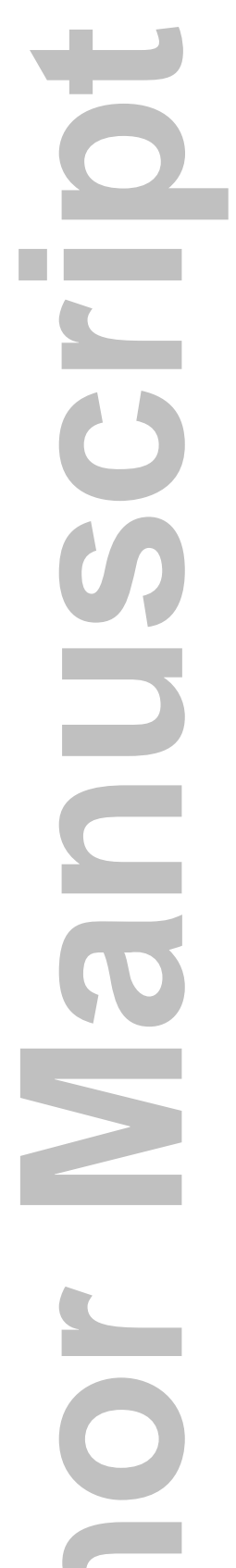

bowel transit normalised to stomach transit

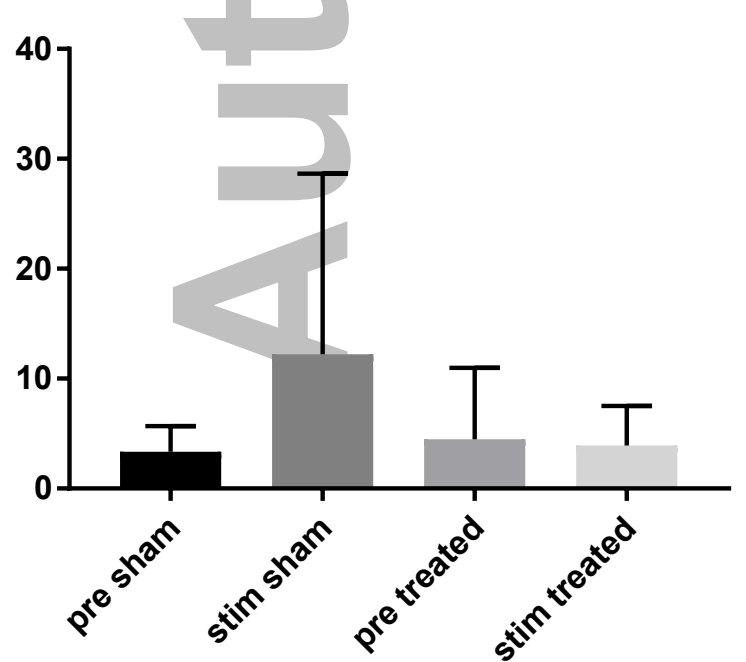

This article is protected by copyright. All rights reserved. bowel transit normalised to stomach transit scatter

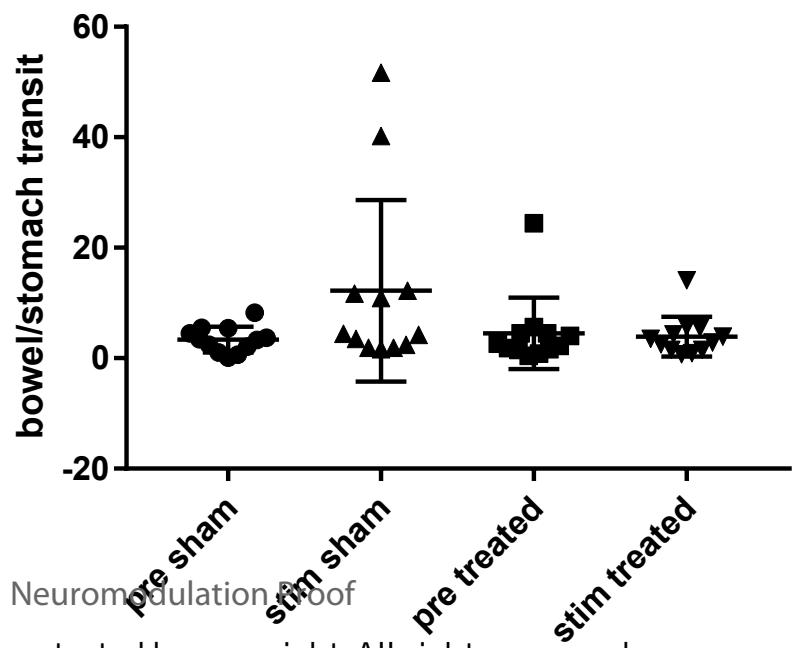




\section{University Library}

\section{- M M N E R VA A gateway to Melbourne's research publications}

Minerva Access is the Institutional Repository of The University of Melbourne

Author/s:

Tan, AYF;Sourial, M;Hutson, JM;Southwell, BR

Title:

Short-Term Interferential Transabdominal Electrical Stimulation Did Not Change Oral-Rectal Transit Time in Piglets

\section{Date:}

2018-10-01

\section{Citation:}

Tan, A. Y. F., Sourial, M., Hutson, J. M. \& Southwell, B. R. (2018). Short-Term Interferential Transabdominal Electrical Stimulation Did Not Change Oral-Rectal Transit Time in Piglets. NEUROMODULATION, 21 (7), pp.669-675. https://doi.org/10.1111/ner.12761.

Persistent Link:

http://hdl.handle.net/11343/283687 